\title{
Correction to: Pasteur's quadrant: an appealing ecophronetic alternative to the prevalent Bohr's quadrant in ecosystem services research
}

\author{
Wei-Ning Xiang
}

Published online: 4 December 2017

(C) Springer Science+Business Media B.V., part of Springer Nature 2017

\section{Correction to: Landscape Ecol}

https://doi.org/10.1007/s10980-017-0583-y

In the original publication, in Fig. 1 caption, the text

"American history scholar Paul Johnson" should be replaced with "British history scholar Paul Johnson".

The original article can be found online at https:// doi.org/10.1007/s10980-017-0583-y.

W.-N. Xiang $(\square)$

Center for Ecophronetic Practice Research, College of Architecture and Urban Planning, Tongji University, Shanghai 200092, China

e-mail: wxiang@uncc.edu; wnxiang@tongji.edu.cn 